\title{
Remote Sensing Monitoring Land Use Changes in the Plain Area of Du Jiang Yan City after the Earthquake
}

\author{
Jiafa Tang \\ Dept. Remote sensing and geospatial information \\ Southwest Jiaotong University \\ Chendu, P.R.China \\ tajava@163.com
}

\author{
Han Xie \\ Dept. Remote sensing and geospatial information \\ Southwest Jiaotong University \\ Chendu, P.R.China \\ 1045372604@qq.com
}

\begin{abstract}
The plain area of the Du Jiang Yan city was the key area of the reconstruction area after the 2008's earthquake, so the land use in this area had experienced a large-scale and fast change from 2009 to 2012 . Two temporal remote sensing images, taken by the HJ satellite in the April of 2009 and 2012, are used to extract the land use information and to detect changes, some landscape metrics, produced by the FRAGSTATS, are employed to estimate the affections brought by the changes. The results show that about 2983 ha farm lands have been transferred to the built-up lands during the research time and the landscape of the farm lands have become more complex. It is a serious problem that should be faced by the local government, because the significant loss of the farm land is acted counter to strict protection policy of the farm land.
\end{abstract}

Key words-plain area of Du Jiang Yan, remote sensing, land use and landscape, change detection

\section{INTRODUCTION}

Du Jiang Yan city was one of the hardest destroyed area in the 2008's earthquake; the land use had big changes for this reason, some studies have discussed these changes. Pan Qian et al. [1] used the Landsat TM images of different times, one was the "before earthquake" and another was "after earthquake", to access and estimate the damage to the land use brought by the earthquake. The study showed that about $66254 \mathrm{hm}^{2}$ of forest land was destroyed. Ni Zhong run's [2] research showed that about $1300 \mathrm{hm}^{2}$ of farm land, $600 \mathrm{hm}^{2}$ of built-up land were destroyed. The damaged forest lands were mostly located in the mountain area, and the destroyed farm lands and the builtup lands were mostly in the plain area.

After the earthquake, the Chinese government started a large scale reconstruction in the destroyed area, so the plain area of Du Jiang Yan city, with the nice geographical conditions, was one of the key areas of the reconstruction. From 2008 to 2012, the plain area of Du Jiang Yan experienced a very fast process of the urbanization and the land use in this area also had bigger changes than ever before. Li Zhe et al. [3] used the remote sensing data from 2004 to 2010 to estimate the land use change rate of the before and after earthquake. The result showed that the rate of land use change before the earthquake was $0.24 \%$ per year, while the rate after earthquake was $0.5 \%$. Li Wei et al. [4] used the remote sensing data of 2007 and 2010 to detect the changed that happened in plain area during the period, and found that the construction area had a $2.11 \%$ promotion, while the farm land had a $1.93 \%$ reduction.

The reconstruction time defined by the government was from 2009 to 2012. The researches above mentioned are mostly about the changes occurred in the first half reconstruction time, more details about the whole time are needed to estimate the effects and the reasonableness of the land use changes. The objectives of this study are to detect the land use changes occurred in the plain area of the Du Jiang Yan city from 2009 to 2012, to estimate the effects that brought by the land use changes through the landscape analysis.

\section{SITE DESCRIPTION}

Du Jiang Yan city, with the geographic coordinate of $103^{\circ} 25^{\prime} 42^{\prime \prime} \mathrm{E} \sim 103^{\circ} 47^{\prime} 0^{\prime \prime} \mathrm{E}$ and $31^{\circ} 44^{\prime} 54^{\prime \prime} \mathrm{N}$ $\sim 31^{\circ} 02^{\prime} 9^{\prime \prime} \mathrm{N}$, is located in the northwest of the Sichuan basin. The northwest of the city is the mountain area; the southeast is the plain area. The plain area is the research area of this paper, it covers about $441 \mathrm{~km}^{2}$. The land use types in this area include water body, forest land, farm land and built-up land. The urbanization rate in 2008 was about 46\%, most population of the city lived in rural area, so the residential area was widely spread in the plain. All these things had a great change since 2008 because of the earthquake and the large scale reconstruction after the earthquake. The local government aimed to promote the urbanization rate to $80 \%$ in 2015 , so in the past 5 years, many lands that used to be the farm lands have been changed to the built-up lands, new towns and big rural communities have been built up in these changed areas, and at the same time, some former built-up lands have been changed to the farm lands, a lot of little rural residential areas disappeared. Generally speaking, the land use pattern has a great change since 2008 .

\section{DATA PREPARATION AND IMAGE INTERPRETATION}

\section{A. Data Preparation}

The remote sensing image used for the research is the HJ satellite image with the spatial resolution of $30 \mathrm{~m}$, it has four bands: blue light, red light, green light and infrared light. The data used in this paper was taken by the HJ-A satellite in 201204-21(Path number: 13-80) and 2009-04-29(Path number: 1380).The Sichuan basin has nearly about 250 cloudy days a year; it is not easy to get clear image in the summer and winter 
seasons. The two images used in this study were both taken in the April, which was the late spring season. The crops in the farm lands grew well in this season, it was helpful to the image interpretation.

Accurate per-pixel registration of multi-temporal remote sensing data is essential for change detection since the potential exists for registration errors to be interpreted as land cover and land use change, leading to an overestimation of actual change [5]. In this study, the two temporal remote sensing images were registered image to image; the resultant root mean squared error of each image was less than 0.3 pixels. Then the two images were projected to the Gauss projection system based on 1:100,000 scale topographic maps. The administrative map of Du Jiang Yan (the scale is 1:100,000) and the Aster GDEM which was got from the USGS website, were also registered with the satellite images, then the area with the altitude lower than $800 \mathrm{~m}$ of the city was subset from the image and that was the images of the research area of this study (Fig 1).

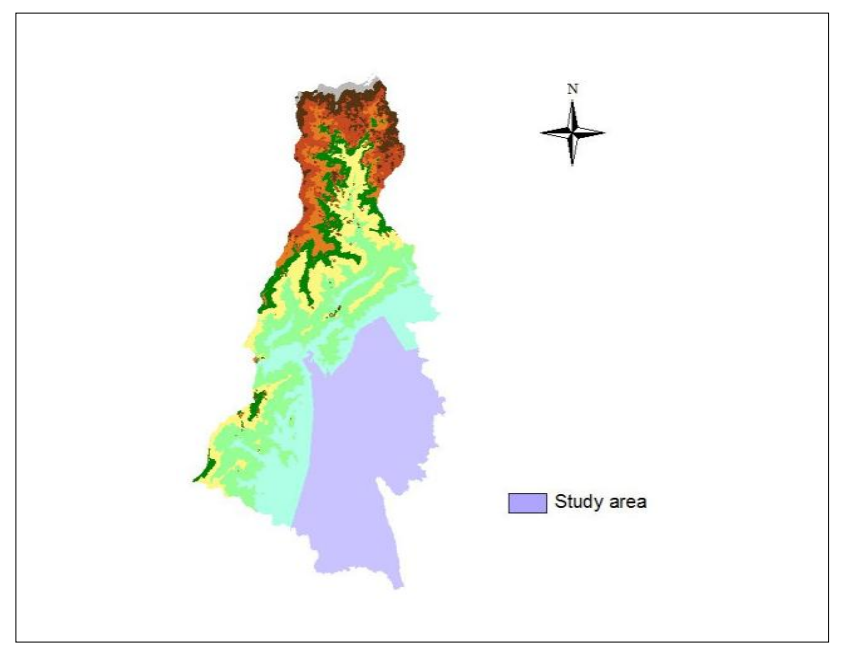

Fig. 1. The plain area of Du Jiang Yan city

\section{B. Image Interpretation}

According to the national land use classification standard and the image analysis of the research area, the land would be classified as four types: the farm land, the forest land, the water body and the built-up land (including the towns, factories, roads and rural residents). All these types of lands were easy to be interpreted in the false color image. Three bands of the HJ image (infrared light band, red light band and green light band) were used to composite the false color image.

Because the two temporal images were taken nearly at the same time of the spring season, the same land use type had almost the same color in the images. In the false color image, the farm lands had the pink color. The main water bodies in the research area were the rivers and irrigate channels, and they had the blue black color in the false color image. The residential area were widely spread in the whole area, the color of them was steel grey or white, some buildings under the construction had the deep green or fresh green color. The road could also be regarded as a kind of built-up land, and it had the same color with residential area in the false color image. The forest land had two colors: deep red and fresh red in the image, it may be caused by the variety or the age of the forest.

In order to improve the accuracy of the interpretation, each land use type was divided into several subtypes according the image analysis. The farm land had 2 subtypes, the forest land had 2 subtypes, the water body had 2 subtypes and the built-up land had 5 subtypes. The maximum likelihood method was used for the land use classification. Training site data were collected by means of on-screen selection of the point mode using the software of ENVI. Totally, 186 training sites were chosen for each image to ensure that 11 spectral classes constituting each land use category were adequately represented in the training statistics. The KAPPA indices for the 2009 and 2012 were 0.82 and 0.86 respectively.

The pixels in the image corresponding to the typical land use types of the ground had the typical colors, and these pixels were easy to be interpreted. All the land use types were mixed together in the ground and the imaging time was the spring, for this reason, some pixels in the images which corresponding to the edges of the different types didn't have the typical color, it brought some confusion to the interpretation of these pixels. These confused pixels were identified by the high resolution images of the Google Earth and the 20 fields' data which mostly located in the Tian Ma town, Chong Yi town, Guan Kou town and $\mathrm{Pu}$ Yang town.

The rivers and the irrigate channels were discontinuous in the images, so the machine interpretation results of these two kinds of water bodies were also discontinuous in the result maps. The flood plains had the same color with some kinds of buildings, so they were always be misinterpreted as the built-up lands. In order to increase the accuracy of interpretation, these mistakes were corrected in the following visual interpretation and the results were integrated with the machine classification results using GIS. Fig 2 and Fig 3 are the interpretation results of the 2009 and 2012.

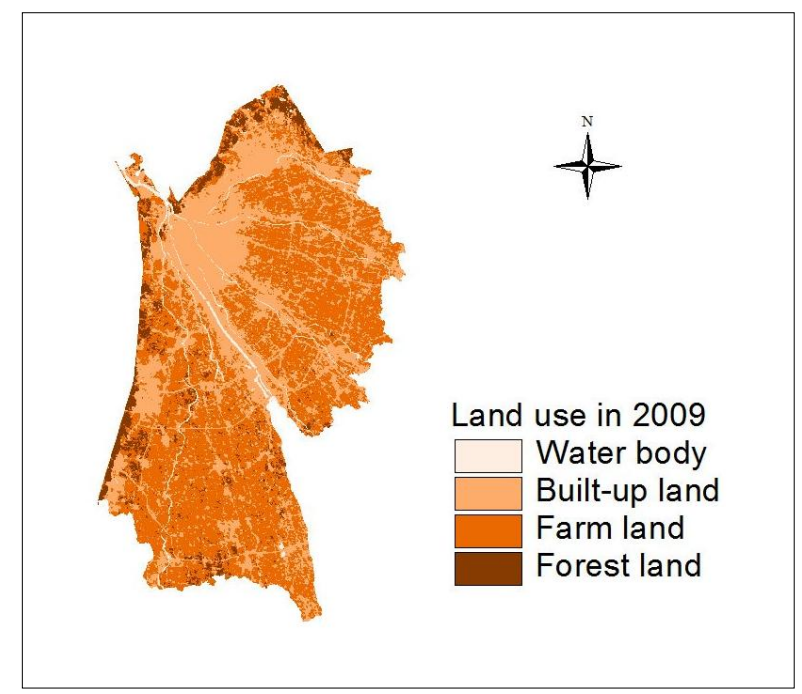

Fig. 2. The plain area land use of Du Jiang Yan city in 2009 


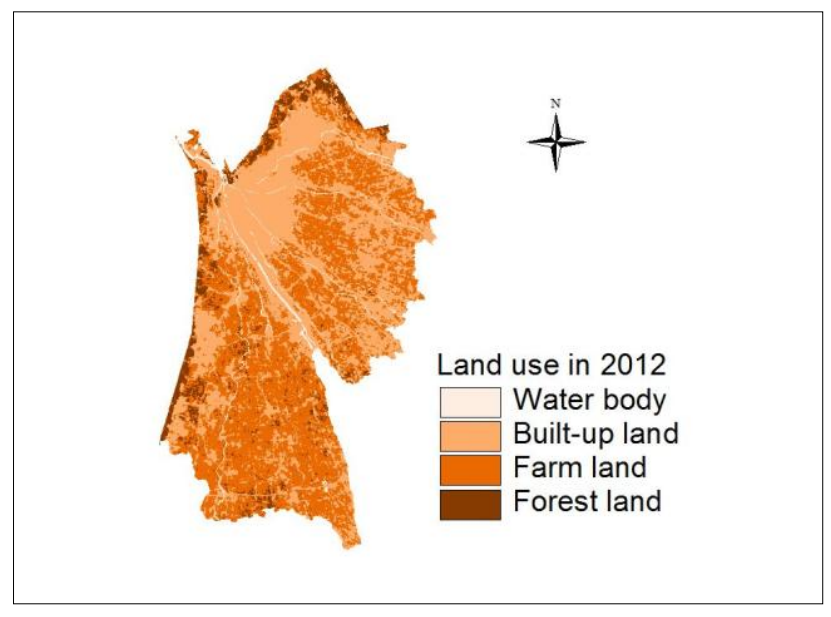

Fig. 3. The plain area land use of Du Jiang Yan city in 2012

\section{RESULT AND DISCUSSION}

\section{A. Land Use Changes in the Plain Area of Du Jiang Yan City}

The quantification of land use change for the analyzed categories is given in Table I.

TABLE I. Area Measurement Of Land Use Within The Plain Area OF THE DU JIANG YAN CITY IN 2009 AND 2012

\begin{tabular}{|c|c|c|c|c|c|c|}
\hline \multirow{2}{*}{ Categories } & \multicolumn{2}{|c|}{2009} & \multicolumn{2}{|c|}{2012} & \multicolumn{2}{|c|}{$\begin{array}{l}\text { Changes in } \\
2009-2012\end{array}$} \\
\hline & Area(ha) & $\begin{array}{c}\text { Area } \\
(\%)\end{array}$ & Area(ha) & $\begin{array}{c}\text { Area } \\
(\%)\end{array}$ & $\operatorname{Area}(h a)$ & $\begin{array}{c}\text { Area } \\
(\%)\end{array}$ \\
\hline Farm Land & 23198.14 & 52.64 & 20214.36 & 45.87 & $\begin{array}{l}- \\
2983.78\end{array}$ & $\begin{array}{l}- \\
6.77\end{array}$ \\
\hline $\begin{array}{l}\text { Built-up } \\
\text { land }\end{array}$ & 17399.97 & 39.49 & 20383.65 & 46.26 & 2983.68 & 6.77 \\
\hline $\begin{array}{l}\text { Forest } \\
\text { Land }\end{array}$ & 2567.25 & 5.83 & 2568.87 & 5.83 & 1.62 & 0.00 \\
\hline $\begin{array}{l}\text { Water } \\
\text { body }\end{array}$ & 900.80 & 2.04 & 899.28 & 2.04 & -1.52 & 0.00 \\
\hline
\end{tabular}

The forest land, which was mainly distributed in the transitional zone of the Long Men Mountain to the Chen Du alluvial plain, had little changes during the study period due to the strict control of land use change by the government. The water body almost had no changes for the same reason. The sum of these two types occupied a small ratio in the whole area. The built-up land was the second largest class in 2009 (17399.97 ha), but it became the largest class in 2012, and the area increased to 20383.35 ha.

Meanwhile, the farm land which was largest class in 2009 (23198.14ha) decreased to the second largest class, and the area decreased to 20214.36 ha. The decreased area of the farm land almost equaled to the increased of the built-up land, it meant that all the loss of the farm land were transferred to built-up land. The shifts of these two types land were owed to the large scale and the fast process of the urbanization and industrialization which was prompted powerfully by the local government after the earthquake.

However, the simple detection of change is rarely sufficient in itself: information is generally required about the initial and final for the "from-to" analysis. In order to know what happened and where happened in the research area, the two temporal interpretation maps were overlaid with the algorithm of minus, and the Fig 4 is the result map. The grey area in the Fig 4 is the no change area, it is about 33952 ha. The red area is the area of the "from farm land to built-up land", it occupies about 6548 ha. The changes were most occurred in the towns of the Tian Ma, Chong Yi, Qing Chen Shan, Yu Tang and Pu Yang. Many new towns and rural residents, factories, roads were built in these areas. On the other hand, about 3565 ha built-up lands were changed to farm lands because of the rural residential land arrangement. It was occurred widely in the study area; this meant a lot of the rural residents had disappeared in the research period.

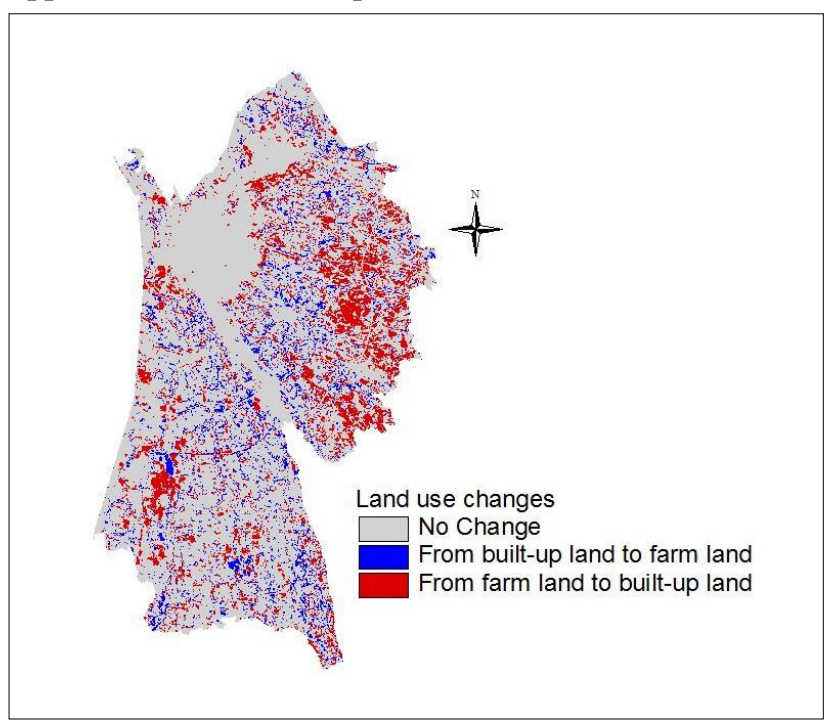

Fig. 4. The land use changes in the plain area of Du Jiang Yan city

\section{B. The Land Scape Changes in the of Du Jiang Yan City}

Most researchers used landscape indices to describe and estimate landscape changes [6,7]. The FRAGSTATS, developed by the Forest Science Department, Oregon State University, U.S.A., can calculate more than 40 landscape metrics. However, many of them are highly correlated [8, 9]. In order to estimate the geospatial character changes of the landscape brought by the land use changes, the landscape metrics, including the NP, MPS, AWMSI, and AI, which described the character of the patch density, size, shape and the diversity separately, were selected in the research. Table II is the landscape metrics at landscape level in 2009 and 2012. Table III is the landscape metrics at class level in 2009 and 2012.

In the Table II, NP (the patch numbers) decreases a lot and the MPS (mean patch size) increase, it implies that the landscape fragmentation decrease a lot at the landscape level. Things are very differently at the class level. In the Table III, the NP of the farm land increases from the 1540 to 1766 , and it's MPS decreases from 15.05 to 11.44 , the landscape of the farm land in 2012 is more fragmented than that in 2009. In the contrast, the NP of the built-up land decreases from the 3194 to 1431, and it's MPS increases from 5.44 to 14.25 , that means the landscape of the built-up land in 2012 is fewer fragmented 
than that in 2009. The NP and MPS of the forest land and water body only have little changes.

At the landscape level, the AWMSI increases from 16.74 to 18.47 , and this means the patches shape is more complex from 2009 to 2012 at the landscape level. The change of this index is mainly caused by the big increase of the farm land in the Table III. The AWMSI in Table III shows that the patches shape of the farm land become more complex, while the patches shape of the built-up land become simpler in 2012. The forest land and water body almost have no change in this index.

ALL the AI index in the Table II and Table III have a little promotion except the water body. It shows that the aggregation degree has a little promotion both at the landscape level and at the class level.

TABLE II. LANDSCAPE Metrics At LANDSCAPE LEVEL IN 2009 AND 2012

\begin{tabular}{|l|l|l|l|l|}
\hline \multicolumn{1}{|c|}{ Year } & \multicolumn{1}{|c|}{$\boldsymbol{N P}$} & \multicolumn{1}{c|}{ MPS/hm2 } & \multicolumn{1}{c|}{ AWMSI } & \multicolumn{1}{c|}{ AI/\% } \\
\hline 2009 & 6439 & 6.85 & 16.74 & 86.08 \\
\hline 2012 & 4911 & 8.96 & 18.47 & 87.53 \\
\hline
\end{tabular}

TABLE III. LANDSCAPE Metrics At Class LeVEl In 2009 And 2012

\begin{tabular}{|l|l|c|c|c|c|}
\hline Categories & Year & $\boldsymbol{N P}$ & $\boldsymbol{M P S}_{\mathbf{h} \boldsymbol{m}^{\mathbf{2}}}$ & $\boldsymbol{A W M S I}$ & $\boldsymbol{A I} / \boldsymbol{\%}$ \\
\hline \multirow{3}{*}{ Farm Land } & 2009 & 1540 & 15.05 & 12.39 & 88.14 \\
\cline { 2 - 6 } & 2012 & 1766 & 11.44 & 26.85 & 89.53 \\
\hline \multirow{2}{*}{$\begin{array}{l}\text { Built-up } \\
\text { land }\end{array}$} & 2009 & 3194 & 5.44 & 25.01 & 85.80 \\
\cline { 2 - 6 } & 2012 & 1431 & 14.25 & 12.58 & 87.91 \\
\hline \multirow{3}{*}{ Forest Land } & 2009 & 1535 & 1.67 & 4.10 & 75.69 \\
\cline { 2 - 6 } & 2012 & 1541 & 1.67 & 4.07 & 75.74 \\
\hline \multirow{3}{*}{ Water body } & 2009 & 170 & 5.35 & 5.27 & 68.04 \\
\cline { 2 - 6 } & 2012 & 173 & 4.97 & 5.09 & 67.42 \\
\hline
\end{tabular}

\section{CONCLUSION AND DisCUSSION}

The plain area of the DU Jiang Yan city was the key area of the reconstruction area after the earthquake, so the land use in this area experienced a large-scale and fast change from 2009 to 2012 .

The detection of the land use changes show that about 2983 ha farm lands have been transferred to the built-up lands during the research time. More details about these changes are showed in the "from-to" analysis, about 6548 ha farm lands were transferred to the built-up land, and most of these changes were occurred in the towns of Tian Ma, Chong Yi, Qing Chen Shan, $\mathrm{Yu}$ Tang and $\mathrm{Pu}$ Yang. On the other hand, about 3565 ha builtup lands were changed to farm lands, and these changes were widely spread in the study area.

Some landscape metrics are employed to estimate the affections brought by the land use changes. At the class level, the landscape of the farm land in 2012 is more fragmented than that in 2009, and its patches shape of the farm land become more complex; while the landscape of the built-up land in 2012 is fewer fragmented than that in 2009 and its patches shape become simpler in 2012 .

The big loss of the farm land is a serious problem that should be faced by the local government, because the number of the farm lands of this city has beyond the dead line of the land use planning which has been ratified by the central government, and that is acted counter to strict protection policy of the farm land.

\section{ACKNOWLEDGMENT}

This paper is supported by the Ministry of education of Humanities and social science fund plan (12YJAZH124) and the Fundamental Research Funds for the Central Universities (A0920502051308-12).

\section{REFERENCES}

[1] Pan Qian, Zhang Qiu-jin, Xu Liang, Basing on RS \& GIS Monitoring of Ecological Restoration in very Disaster-hit Area of Wenchuan Earthquake, 2012, Si Chuan Environment, vol.31 (4), pp.29-22, Aug 2012[Chinese]

[2] Ni Zhong- yun, HE Zheng- wei, Zhao Yin- bing, Wang Le, Gao Hui, Cai Ke- ke, The Information Extraction Method for Land Use and Cover Change ( LUCC) after the Earthquake in Dujiang Dam, Remote sensing for lands and resources, vol. 83, pp.73-76, Mar 2010 [Chinese].

[3] Li Zhe, He Zheng-wei, Xu Hui-xi, The Research of Land Use Dynamic Change before and after the Earthquake in Dujiangyan City, Journal of Sichuan Normal University( Natural Science), vol.35(3), pp.412-417, May 2012[Chinese].

[4] Liu Wei, Luo Hong-bing, Liu Xia, Liu Xiao-ling4, Huang Bo, Analysis of the Earth Surface Coverage Changes before and after the Earthquake in Dujiangyan City on May 12th, 2008, Si Chuan Environment, vol.30(6), pp.69-75, Dec 2011[Chinese].

[5] Stow, D. A. Reducing mis-registration effects for pixel-level analysis of land-cover change, International Journal of Remote Sensing, Vol.20, pp: 2477-2483, May, 1999.

[6] Xia Li, Anthony Gar-On Yeh, Analyzing spatial restructuring of land use patterns in a fast growing region using remote sensing and GIS, Landscape and Urban Planning, vol. 69, pp: 335-354, 2004

[7] Xiao Hui-he, Ya Jun-gao, Jin Xing-niu, Yan Feng-zhao Landscape Pattern Changes under the Impacts of Urbanization in the Yellow River Wetland-taking Zhengzhou as an example, Procedia Environmental Sciences, vol.10 ,pp: 2165 - 2169,2011

[8] USEPA (U.S. Environmental Protection Agency), Landscape monitoring and assessment research plan, EPA 620/R-94/009, Office of Research and Development, Washington, D.C.1994.

[9] Riitters, K.H., O’Neill, R.V., Hunsaker, C.T., Wickham, J.D., Yankee, D.H., Timmins, S.P.,Jones, K.B. \& Jackson, B.L, A factor analysis of landscape pattern and structure metrics, Landscape Ecology, vol. 10,pp: 23-39, 1995 